\title{
Asenapine effects on individual Young Mania Rating Scale items in bipolar disorder patients with acute manic or mixed episodes: a pooled analysis
}

\author{
This article was published in the following Dove Press journal: \\ Neuropsychiatric Disease and Treatment \\ 27 March 2013 \\ Number of times this article has been viewed
}

Pilar Cazorla

Jun Zhao

Mary Mackle

Armin Szegedi

Merck, Rahway, NJ, USA
Correspondence: Armin Szegedi Merck, I26 E Lincoln Avenue,

Rahway, NJ, USA

Tel +l 7325945825

Fax +l 7325945770

Email armin.szegedi@merck.com
Background: An exploratory post hoc analysis was conducted to evaluate the potential differential effects over time of asenapine and olanzapine compared with placebo on the eleven individual items comprising the Young Mania Rating Scale (YMRS) in patients with manic or mixed episodes in bipolar I disorder.

Methods: Data were pooled from two 3-week randomized, controlled trials in which the eleven individual items comprising the YMRS were measured over 21 days. An analysis of covariance model adjusted by baseline value was used to test for differences in changes from baseline in YMRS scores between groups.

Results: Each of the eleven individual YMRS item scores was significantly reduced compared with placebo at day 21. After 2 days of treatment, asenapine and olanzapine were superior to placebo for six of the YMRS items: disruptive/aggressive behavior, content, irritability, elevated mood, sleep, and speech.

Conclusion: Reduction in manic symptoms over 21 days was associated with a broad-based improvement across all symptom domains with no subset of symptoms predominating.

Keywords: asenapine, Young Mania Rating Scale, bipolar disorder, YMRS, antipsychotic, olanzapine

\section{Introduction}

The Young Mania Rating Scale (YMRS) is a diagnostic questionnaire commonly used to evaluate manic symptoms in patients with bipolar 1 disorder and to assess treatment efficacy in clinical trials. This rating scale comprises eleven items (elevated mood, increased motor activity - energy, sexual interest, sleep, irritability, speech - rate and amount, language-thought disorder, content, disruptive-aggressive behavior, appearance, and insight). The total YMRS score is calculated as the summation of each of the eleven individual item scores. ${ }^{1}$

Asenapine is a tetracyclic antipsychotic with a unique pharmacologic profile indicated in several countries, including the United States and the European Union, for use in adult patients with manic episodes in bipolar I disorder. Acute efficacy was demonstrated in two 3-week trials in which asenapine monotherapy was significantly more effective than placebo at improving mania symptoms as assessed using the total YMRS score. ${ }^{2,3}$ The objective of this exploratory, post hoc analysis of the data pooled from the two positive trials was to identify the potential differential effects of asenapine or olanzapine on each of the eleven individual YMRS items, as indicators of the severity of specific bipolar mania symptom dimensions. 


\section{Materials and methods}

Data were pooled from two 3-week randomized, placeboand olanzapine-controlled, double-blind, double-dummy, multicenter, parallel-group trials (A7501004 and A7501005). ${ }^{2,3}$ Patients aged $\geq 18$ years with a diagnosis of bipolar I disorder; current manic or mixed episodes according to the Mini International Neuropsychiatric Interview ${ }^{4}$ and Diagnostic and Statistical Manual of Mental Disorders, Fourth edition, text revision criteria ${ }^{5}$; and a YMRS total score $\geq 20$ at screening and baseline were eligible. Following a 7-day, single-blind placebo run-in phase, active treatment was initiated (day $1, \mathrm{n}=977$ ) with asenapine $20 \mathrm{mg}(10 \mathrm{mg}$ twice daily [BID], morning and evening; $\mathrm{n}=379)$, olanzapine $15 \mathrm{mg}$ (once daily [QD]; $\mathrm{n}=396)$, or placebo $(\mathrm{n}=202$ ). Thereafter, treatment continued with flexible dosing (asenapine at 10-20 mg daily [5-10 mg BID] and olanzapine at 5-20 mg QD). Patients remained in the research facility for $\geq 7$ days of treatment and were discharged if clinically stable. A complete description of the design and eligibility criteria of both studies has been reported elsewhere. ${ }^{2,3}$

Seven of the eleven individual YMRS items were scored on a 0 to 4 scale: appearance, insight, language-thought disorder, increased motor activity - energy, elevated mood, sleep, and sexual interest. The remaining four items were scored on a 0 to 8 scale: disruptive-aggressive behavior, content, irritability, and speech - rate and amount. The YMRS total score, with a range of 0 to 60 , was a summation of each of the eleven individual scores, with the higher total YMRS scores reflecting greater symptom severity. YMRS response rate was determined as the percentage of patients achieving $\geq 50 \%$ reduction from baseline in total YMRS score.

An exploratory post hoc analysis of the change from baseline in the eleven individual YMRS items was performed. An analysis of covariance model adjusted by baseline value was used to test for differences in changes from baseline in YMRS scores between groups. Last observations were carried forward (LOCF) for missing data. The results have not been corrected for multiplicity.

\section{Results}

\section{Patient characteristics}

Pooled patient demographics and baseline characteristics are displayed in Table 1. Of the 977 treated patients, $680(70 \%)$ completed the studies. The modified intent-to-treat population (treated patients with at least one post baseline YMRS assessment, $\mathrm{n}=960$ ) consisted of patients receiving asenapine 10 to $20 \mathrm{mg}$ daily ( $\mathrm{n}=372)$, olanzapine 5 to $20 \mathrm{mg}$ daily $(n=391)$, or placebo $(n=197)$.
Table I Pooled demographic and baseline characteristics (intentto-treat)

\begin{tabular}{|c|c|c|c|}
\hline & Placebo & $\begin{array}{l}\text { Asenapine } \\
10-20 \text { mg daily }\end{array}$ & $\begin{array}{l}\text { Olanzapine } \\
\text { 5-20 mg daily }\end{array}$ \\
\hline Sex, N & 197 & 372 & 391 \\
\hline Female, n (\%) & $99(50.3)$ & $169(45.4)$ & $16 \mid(4 \mid .2)$ \\
\hline Male, n (\%) & $98(49.7)$ & $203(54.6)$ & $230(58.8)$ \\
\hline Race, $\mathrm{N}$ & 197 & 372 & 391 \\
\hline Asian, n (\%) & $4 \mid(20.8)$ & $75(20.2)$ & $78(19.9)$ \\
\hline Black, n (\%) & $34(17.3)$ & $67(18.0)$ & 7I (I8.2) \\
\hline White, n (\%) & $110(55.8)$ & $221(59.4)$ & $221(56.5)$ \\
\hline Other, n (\%) & $12(6.1)$ & $9(2.4)$ & $21(5.4)$ \\
\hline Age group & 197 & 372 & 391 \\
\hline 18-64 years, n (\%) & $193(98)$ & $365(98.1)$ & $386(98.7)$ \\
\hline$\geq 65$ years, $\mathrm{n}(\%)$ & $4(2)$ & $7(1.9)$ & $5(1.3)$ \\
\hline Age, $N$ & 197 & 372 & 391 \\
\hline Years, mean (SD) & $38.7(12.2)$ & $38.8(12.1)$ & $39.2(11.1)$ \\
\hline Current episode, $\mathrm{N}$ & 197 & 372 & 391 \\
\hline Manic, n (\%) & $|3|(66.5)$ & $265(71.2)$ & $269(68.8)$ \\
\hline Mixed, n (\%) & $66(33.5)$ & $107(28.8)$ & $122(31.2)$ \\
\hline Weight, $N$ & 197 & 372 & 391 \\
\hline $\mathrm{Kg}$, mean (SD) & $78(19.5)$ & $76.9(19.3)$ & $78.9(19.9)$ \\
\hline BMI, N & 196 & 371 & 389 \\
\hline $\mathrm{Kg} / \mathrm{m}^{2}$, mean $(\mathrm{SD})$ & $27.3(6.1)$ & $26.5(5.5)$ & $27.2(5.9)$ \\
\hline
\end{tabular}

Abbreviations: BMI, body mass index; SD, standard deviation.

\section{YMRS item results}

Reductions from baseline to day 21 were significantly greater for asenapine and olanzapine compared with placebo for each of the eleven individual YMRS items (Table 2). Statistically significant reductions in YMRS total score were observed for both treatments compared with placebo, as reported previously. ${ }^{2,3}$

In six of the YMRS items, statistically significant improvements from baseline were observed as early as Day 2 (mean change \pm SD, LOCF) for asenapine (10-20 mg daily) and olanzapine (5-20 mg daily) compared with placebo: disruptive-aggressive behavior $(-0.3 \pm 1.15 ;-0.4 \pm 1.14$; $-0.1 \pm 1.16)$, content $(-0.4 \pm 1.22 ;-0.5 \pm 1.48 ;-0.2 \pm 0.90)$, irritability $(-0.5 \pm 1.41 ;-0.5 \pm 1.33 ;-0.3 \pm 1.15)$, elevated mood $(-0.3 \pm 0.75 ;-0.3 \pm 0.73 ;-0.1 \pm 0.63)$, sleep $(-0.4 \pm 0.88 ;-0.5 \pm 0.92 ;-0.2 \pm 0.74)$, and speech $(-0.6 \pm 1.23 ;-0.6 \pm 1.27 ;-0.1 \pm 0.96)$ (all comparisons $P<0.05$ for asenapine or olanzapine versus placebo).

No statistical difference was observed in the improvements seen with asenapine and olanzapine in the YMRS items of appearance, content, elevated mood, increased motor activity and insight. For the remaining items (language-thought disorder, sleep, sexual interest, disruptive-aggressive behavior, irritability, and speech) while both treatments were associated with significant improvement compared to placebo, olanzapine treatment was accompanied by a 
Table 2 Change in Young Mania Rating Scale (YMRS) score at day 2 I (last observation carried forward, intent-to-treat)

\begin{tabular}{|c|c|c|c|}
\hline & $\begin{array}{l}\text { Placebo } \\
N=197\end{array}$ & $\begin{array}{l}\text { Asenapine } \\
\text { I0-20 mg daily } \\
N=372\end{array}$ & $\begin{array}{l}\text { Olanzapine } \\
\text { 5-20 mg daily } \\
N=39 \mid\end{array}$ \\
\hline Day $21, \mathrm{n}$ & 197 & 372 & 391 \\
\hline \multicolumn{4}{|l|}{ Total YMRS score (0-60) } \\
\hline Baseline mean (SD) & $28.7(6.2)$ & $28.8(6.2)$ & $29.2(6.3)$ \\
\hline LS mean change (SE) & $-6.7(0.75)$ & $-11.2(0.54)$ & $-13.6(0.53)$ \\
\hline$P$-value (versus placebo) & & $<0.0001$ & $<0.0001$ \\
\hline$P$-value (versus olanzapine) & & 0.0013 & \\
\hline \multicolumn{4}{|l|}{ Appearance $(0-4)$} \\
\hline Baseline mean (SD) & $1.2(0.80)$ & $1.2(0.86)$ & $1.3(0.94)$ \\
\hline LS mean change (SE) & $-0.3(0.06)$ & $-0.5(0.04)$ & $-0.6(0.04)$ \\
\hline$P$-value (versus placebo) & & 0.0042 & $<0.0001$ \\
\hline$P$-value (versus olanzapine) & & 0.0518 & \\
\hline \multicolumn{4}{|l|}{ Insight (0-4) } \\
\hline Baseline mean (SD) & $1.0(1.26)$ & I.I (I.38) & I.I (I.36) \\
\hline LS mean change (SE) & $-0.2(0.06)$ & $-0.4(0.04)$ & $-0.5(0.04)$ \\
\hline$P$-value (versus placebo) & & 0.0035 & $<0.0001$ \\
\hline$P$-value (versus olanzapine) & & 0.115 & \\
\hline \multicolumn{4}{|c|}{ Language-thought disorder (0-4) } \\
\hline Baseline mean (SD) & $2.1(0.63)$ & $2.1(0.66)$ & $2.1(0.70)$ \\
\hline LS mean change (SE) & $-0.5(0.06)$ & $-0.8(0.05)$ & $-1.0(0.05)$ \\
\hline$P$-value (versus placebo) & & 0.0008 & $<0.0001$ \\
\hline$P$-value (versus olanzapine) & & 0.0078 & \\
\hline \multicolumn{4}{|c|}{ Increased motor activity - energy $(0-4)$} \\
\hline Baseline mean (SD) & $2.8(0.69)$ & $2.8(0.7 \mathrm{I})$ & $2.8(0.66)$ \\
\hline LS mean change (SE) & $-0.8(0.09)$ & $-1.1(0.06)$ & $-1.2(0.06)$ \\
\hline$P$-value (versus placebo) & & 0.0023 & $<0.0001$ \\
\hline$P$-value (versus olanzapine) & & 0.12 & \\
\hline \multicolumn{4}{|l|}{ Elevated mood (0-4) } \\
\hline Baseline mean (SD) & $2.6(0.88)$ & $2.7(0.86)$ & $2.6(0.85)$ \\
\hline LS mean change (SE) & $-0.6(0.08)$ & $-1.0(0.06)$ & $-I . I(0.05)$ \\
\hline$P$-value (versus placebo) & & 0.0002 & $<0.0001$ \\
\hline$P$-value (versus olanzapine) & & 0.2696 & \\
\hline \multicolumn{4}{|l|}{ Sleep $(0-4)$} \\
\hline Baseline mean (SD) & $2.3(0.84)$ & $2.2(0.92)$ & $2.2(0.92)$ \\
\hline LS mean change (SE) & $-0.6(0.08)$ & $-1.0(0.06)$ & $-1.2(0.06)$ \\
\hline$P$-value (versus placebo) & & $<0.0001$ & $<0.0001$ \\
\hline$P$-value (versus olanzapine) & & 0.0067 & \\
\hline \multicolumn{4}{|l|}{ Sexual interest $(0-4)$} \\
\hline Baseline mean (SD) & $1.5(1.16)$ & $1.5(1.11)$ & $1.6(1.16)$ \\
\hline LS mean change (SE) & $-0.4(0.07)$ & $-0.6(0.05)$ & $-0.8(0.05)$ \\
\hline$P$-value (versus placebo) & & 0.0101 & $<0.0001$ \\
\hline$P$-value (versus olanzapine) & & 0.0178 & \\
\hline \multicolumn{4}{|c|}{ Disruptive-aggressive behavior (0-8) } \\
\hline Baseline mean (SD) & $2.9(1.65)$ & $2.8(1.60)$ & $2.9(1.59)$ \\
\hline LS mean change (SE) & $-0.3(0.13)$ & $-1.0(0.09)$ & $-1.3(0.09)$ \\
\hline$P$-value (versus placebo) & & $<0.0001$ & $<0.0001$ \\
\hline$P$-value (versus olanzapine) & & 0.0134 & \\
\hline \multicolumn{4}{|l|}{ Content $(0-8)$} \\
\hline Baseline mean (SD) & $4.2(2.17)$ & $4.3(2.10)$ & $4.3(2.14)$ \\
\hline LS mean change (SE) & $-0.9(0.15)$ & $-1.7(0.11)$ & $-1.9(0.11)$ \\
\hline$P$-value (versus placebo) & & $<0.0001$ & $<0.0001$ \\
\hline$P$-value (versus olanzapine) & & 0.1517 & \\
\hline \multicolumn{4}{|l|}{ Irritability $(0-8)$} \\
\hline Baseline mean (SD) & $3.9(1.39)$ & $3.7(1.5 I)$ & $4.0(1.40)$ \\
\hline LS mean change (SE) & $-0.8(0.13)$ & $-1.3(0.10)$ & $-1.7(0.09)$ \\
\hline
\end{tabular}


Table 2 (Continued)

\begin{tabular}{|c|c|c|c|}
\hline & $\begin{array}{l}\text { Placebo } \\
N=197\end{array}$ & $\begin{array}{l}\text { Asenapine } \\
\text { 10-20 mg daily } \\
\mathrm{N}=372\end{array}$ & $\begin{array}{l}\text { Olanzapine } \\
\text { 5-20 mg daily } \\
N=391\end{array}$ \\
\hline$P$-value (versus placebo) & & 0.0008 & $<0.0001$ \\
\hline$P$-value (versus olanzapine) & & 0.0127 & \\
\hline \multicolumn{4}{|l|}{ Speech - rate and amount (0-8) } \\
\hline Baseline mean (SD) & $4.2(1.53)$ & $4.3(1.55)$ & $4.3(1.67)$ \\
\hline LS mean change (SE) & $-1.2(0.14)$ & $-1.8(0.10)$ & $-2.1(0.10)$ \\
\hline$P$-value (versus placebo) & & 0.0007 & $<0.0001$ \\
\hline$P$-value (versus olanzapine) & & 0.028 & \\
\hline
\end{tabular}

Abbreviations: LS, least squares; SD, standard deviation; SE, standard error.

significantly greater improvement compared to asenapine ( $P<0.05$ with no multiplicity adjustment).

\section{YMRS response rate}

Following treatment with asenapine or olanzapine a greater response rate ( $\geq 50 \%$ improvement in total YMRS score) was observed compared to placebo $(42.5 \%, 52.4 \%$ and $29.4 \%$ respectively; $P<0.05$ for asenapine or olanzapine versus placebo).

\section{Conclusion}

Reduction in manic symptoms over 21 days was associated with a broad-based improvement across all symptom domains, with no subset of symptoms predominating. For antipsychotics with sedative properties, such as asenapine or olanzapine, it might be suspected that efficacy in manic or mixed episodes would result mainly from effects limited to sleep disturbances and/or aggressive behavior. However, the post hoc analysis presented here suggests that manic and mixed symptom improvement with asenapine or olanzapine is broader and goes beyond effects of sedation, with the complete spectrum of YMRS items showing clinical benefit.

In the present analysis, a subset of YMRS items including disruptive-aggressive behavior, content, irritability, elevated mood, sleep, and speech showed significant differences in favor of asenapine or olanzapine, compared with placebo, as early as the second day of treatment. With both asenapine and olanzapine, improvement seen in the disruptive-aggressive behavior YMRS item was greater than the improvement observed with other YMRS items. Limitations of these analyses include that, as a post-hoc analysis, the hypotheses were not predefined and that the results were not corrected for multiplicity.
Clinicians can therefore expect clinically relevant benefits early in the course of treatment, at least in a subset of patients. In this context, it is worthwhile to mention that early improvement has been reported to be associated with an increased odds ratio of response or remission at the end of treatment. ${ }^{6}$

\section{Acknowledgments}

Medical writing assistance was provided by Karen Pemberton, $\mathrm{PhD}$, of PPSI (a PAREXEL company). The study was funded by Merck. PC is currently employed by Novartis, East Hanover, NJ, USA.

\section{Disclosure}

All authors were employees and shareholders of Merck at the time the study was performed. The authors report no other conflicts of interest in this work.

\section{References}

1. Young RC, Biggs JT, Ziegler VE, Meyer DA. A rating scale for mania: reliability, validity and sensitivity. Br J Psychiatry. 1978;133: 429-435.

2. McIntyre RS, Cohen M, Zhao J, Alphs L, Macek TA, Panagides J. A 3-week, randomized, placebo-controlled trial of asenapine in the treatment of acute mania in bipolar mania and mixed states. Bipolar Disord. 2009;11(7):673-686.

3. McIntyre RS, Cohen M, Zhao J, Alphs L, Macek TA, Panagides J. Asenapine in the treatment of acute mania in bipolar I disorder: a randomized, double-blind, placebo-controlled trial. J Affect Disord. 2010;122(1-2):27-38.

4. Sheehan DV, Lecrubier Y, Sheehan KH, et al. The Mini-International Neuropsychiatric Interview (M.I.N.I.): the development and validation of a structured diagnostic psychiatric interview for DSM-IV and ICD-10. J Clin Psychiatry. 1998;59(Suppl 20):22-33.

5. American Psychiatric Association. Diagnostic and Statistical Manual of Mental Disorders (4th ed, text rev). Washington, DC: American Psychiatric Association; 2000.

6. Zhao J, Ha X, Szegedi A. Early improvement predicts later outcome in manic or mixed episodes associated with bipolar i disorder: post hoc analyses of asenapine studies. Paper presented at: 63rd Annual Institute on Psychiatric Services Meeting. October 27-30, 2011; San Francisco, CA, USA. 
Neuropsychiatric Disease and Treatment

Dovepress

\section{Publish your work in this journal}

Neuropsychiatric Disease and Treatment is an international, peerreviewed journal of clinical therapeutics and pharmacology focusing on concise rapid reporting of clinical or pre-clinical studies on a range of neuropsychiatric and neurological disorders. This journa is indexed on PubMed Central, the 'PsycINFO' database and CAS.

The manuscript management system is completely online and includes a very quick and fair peer-review system, which is all easy to use. Visit http://www.dovepress.com/testimonials.php to read real quotes from published authors.

Submit your manuscript here: http://www.dovepress.com/neuropsychiatric-disease-and-treatment-journal 